\title{
Metastatic Lip Carcinoma
}

National Cancer Institute

\section{Source}

National Cancer Institute. Metastatic Lip Carcinoma. NCI Thesaurus. Code C156088.

A carcinoma that arises from the lip and has metastasized to another anatomic site. 